\title{
Supercritical fluid extraction of polyphenols from lees: overall extraction curve, kinetic data and composition of the extracts
}

\author{
Angela M. Farías-Campomanes ${ }^{1 *}$ (D, Mauricio A. Rostagno ${ }^{2}$, Joel J. Coaquira-Quispe ${ }^{3}$ and M. Angela A. Meireles ${ }^{1}$
}

\begin{abstract}
Background: The increasing incidence of degenerative diseases has attracted the interest in the obtaining of bioactive compounds. Since seeds and skins from grapes are important sources of polyphenols which have been associated with cancer incidence decreasing, then, one of the pisco (alcoholic beverage made of grape) manufacturing byproduct such as lees, could be a potential source of polyphenols. Supercritical fluid extraction is an environmentally friendly technique that has been applied for obtaining polyphenols. Carbon dioxide is used as unique or main extraction solvent instead of organic solvents, most of them toxics and responsible for reducing the application fields of the extracts. For that reason, among others, supercritical fluid extraction is preferred over conventional techniques for obtaining bioactive compounds. The aim of this work was to study the supercritical fluid extraction of polyphenols from lees of pisco-making. Supercritical carbon dioxide with $10 \%$ of ethanol (w/W) was used as extraction solvent. Overall extraction curves were determined at 20 and $35 \mathrm{MPa}$; and the experimental data were used to estimate the kinetic parameters. Conventional techniques using ethanol as extraction solvent were performed for comparative purposes. The extracts were analyzed by thin-layer and high-performance liquid chromatography.

Results: Lower global yield was obtained by supercritical fluid extraction than conventional techniques. From the kinetic parameters, the mass transfer rate and the amount of the extract dissolved in supercritical phase were higher at 20 than $35 \mathrm{MPa}$. Phenolic acids (gallic, protocatechuic, vanillic, syringic, ferulic derivatives and $p$-coumaric derivatives) and flavonoids (quercetin and its derivatives) were identified in the extracts obtained by all extraction techniques. Polyphenols were rapidly extracted with supercritical fluid and more concentrated extracts were obtained at $20 \mathrm{MPa}$. However, for longer extraction times, the highest values of extracted polyphenols were obtained by conventional techniques.
\end{abstract}

Conclusions: Lees from pisco-making are a promising source for recovery polyphenols. Low global yields were obtained when elevated pressures were used. Although supercritical fluid extraction at $20 \mathrm{MPa}$ was the most efficient technique on the extraction of polyphenols from lees of pisco-making due to highly concentrated polyphenols, extracts were rapidly obtained.

Keywords: Supercritical fluid extraction, Ethanol, Polyphenols, Grape lees, Byproducts, Pisco

\section{Background}

Currently, there are several epidemiological studies suggesting an association between the chemical composition

\footnotetext{
*Correspondence: angelam.farias@gmail.com

${ }^{1}$ LASEFI/DEA/School of Food Engineering (FEA), University of Campinas

(UNICAMP), Rua Monteiro Lobato 80, Campinas, SP 13083-862, Brazil

Full list of author information is available at the end of the article
}

of the diet and the incidence of several health conditions such as cancer, cardiovascular diseases, metabolic syndrome and diabetes, among others (Michels and Schulze 2005; Zamora-Ros et al. 2012). Among the most studied, dietary components are polyphenol compounds. These compounds are largely studied because they have been identified to present "in vitro" and "in vivo" properties
勿

(c) 2015 Farías-Campomanes et al. This article is distributed under the terms of the Creative Commons Attribution 4.0 International License (http://creativecommons.org/licenses/by/4.0/), which permits unrestricted use, distribution, and reproduction in any medium, provided you give appropriate credit to the original author(s) and the source, provide a link to the Creative Commons license, and indicate if changes were made. 
such as antioxidant and anti-inflammatory activities that may play a role in disease development and progression (García-Lafuente et al. 2009; Xia et al. 2010).

Among the fruits, grapes are one of the most important sources, not only because the content and diversity of polyphenols, but also because it has a great economic importance due to the worldwide production and use of grapes as raw material for the production of other products, such as wine and distilled beverages. One example of distilled beverage produced from grapes is pisco. The industry of pisco produces a great amount of solid and liquid byproducts that are frequently discarded without any treatment due to its complex composition (Bustamante et al. 2008) and high-cost recovery (Devesa-Rey et al. 2011; Naziri et al. 2004). The main byproducts produced by pisco industry are grape bagasse, lees and stillage. The main difference between wine and pisco production process is that pisco has an additional distillation stage; since distillation occurs after the bagasse and lees formation, then, there is no great difference between grape bagasse and lees obtained from wine and pisco production. Grape bagasse is comprised by skins, seeds and stalks; and is an important source of polyphenols, which are widely recognized by its antioxidant, anticancer, antibacterial activities, among others (Farias-Campomanes and Meireles 2013; Delgado Adamez et al. 2012). Lees are defined as "the residue that forms at the bottom of recipients containing wine, after fermentation, during storage or after authorized treatments, as well as the residue obtained following the filtration or centrifugation of this product" (ECC regulation No. 337/79). For many years, lees from grape processing were seen only as a source of yeast, tartrate, organic molecules and inorganic matter (Silva 2003; Pérez-Serradilla and Luque de Castro 2008). Recent studies proved that they are an important source of polyphenols (phenolic acids and flavonoids), among other antioxidant and bioactive compounds (Yang et al. 2014; Pérez-Serradilla and Luque de Castro 2011; Jia-Jiuan et al. 2009).

Besides conventional extraction methods (Alonso et al. 2002), novel and efficient methods such as microwave-assisted extraction (Pérez-Serradilla and Luque de Castro 2011), ultrasound-assisted extraction (Yang et al. 2014) and supercritical fluid extraction (Jia-Jiuan et al. 2009) have been studied for obtaining antioxidants and polyphenols from lees. Supercritical fluid extraction has been used for obtaining antioxidants from rice wine lees; however, it has not been applied to lees from grape processing, whose antioxidants composition is different. The characteristics of the target compounds must be considered when selecting the extraction method. Polyphenols stability depends on heat, light and oxygen, among other factors. Supercritical fluid extraction (SFE) minimizes the degradation reactions of polyphenols, due to the extraction is performed in a closed extractor without the presence of light and oxygen. Also, since SFE is performed at mild temperatures (however, above the critical temperature of the solvent), then, the degradation of heatsensitive compounds can be reduced. SFE is conducted at pressures above the critical pressure of the extraction solvent. High pressures increase the solvent density and the diffusion coefficient; therefore, the solvation power is increased and a faster extraction is obtained. Also, the extraction selectivity can be altered by small changes of pressure and temperature (Brunner 2005). Another important aspect of the SFE is that it allows separating the extraction solvent from the extract simply by the expansion of the fluid in the extractor vessel outlet. With the pressure drop, the fluid changes to gas and separates from the solids (i.e., extract). This allows the recovery and reusing of the extraction solvent. Carbon dioxide $\left(\mathrm{CO}_{2}\right)$ is the most commonly used solvent in SFE due to its GRAS classification, low critical point (304.2 $\mathrm{K}$ and 7.4 MPa), environmentally friendly features and low cost (Meireles 2007). However, due to carbon dioxide is a non-polar solvent, then, it has low capability for dissolving polar compounds such as polyphenols.

Polar solvents such as ethanol, methanol, water, among others, are widely used as modifiers to improve the extraction efficiency of high polar compounds. Ethanol is the most suitable organic solvent due to its food grade and GRAS classification, and was used on the extraction of polyphenols, providing the best results on polyphenols yield and antioxidants yields (Campos et al. 2008). Due to small amounts (5-15\%) of modifiers (i.e., co-solvent) to alter the solvating power of carbon dioxide are required, the consumption of modifiers during SFE process is still much lower than in conventional extraction techniques. SFE with ethanol as modifier was successfully applied to obtain high-value compounds: polyphenols from grape (Farias-Campomanes et al. 2013; Da Porto et al. 2014; Prado et al. 2012), apple and peach byproducts (Adil et al. 2007), antioxidants from lees of rice wine (Jia-Jiuan et al. 2009) and potato skin (Cardoso et al. 2013), caffeine from tea stalk and fiber wastes (İçen and Gürü 2010), among others.

Therefore, the aim of this work was to study the extraction of polyphenols from lees derived from Peruvian pisco-making using supercritical carbon dioxide and ethanol as modifier; and compare with conventional techniques in terms of global yield and polyphenols composition of the extracts. 


\section{Methods \\ Material \\ Biological material}

Lees from the manufacturing of pisco (using Vitis vinifera grapes) in 2010 were provided by Bodega y Viñedos Candela S.A (Lima, Peru). Lees were collected after fermentation stage and stored in dark plastic tanks. Then, lees were carried out to Agroindustrial Development Institute (INDDA by its initials in Spanish), Lima, Peru, for freeze drying. The powder material was transported to the Laboratory of Supercritical Technology: Extraction, Fractionation and Identification of Extracts Laboratory (LASEFI by its initials in Portuguese) of University of Campinas (UNICAMP). At LASEFI, the samples were stored in a domestic freezer at $253 \mathrm{~K}$ to be used later in the experiments.

\section{Chemicals}

All chemicals used in the experiments and TLC and HPLC analyses are shown in Table 1.

\section{Raw material characterization}

Particle size distribution was determined using a vibratory system (Bertel, model 1868, Carreiras, Brazil) equipped with a set of Tyler sieves series (Tyler series, Wheeling, USA) with mesh apertures of 16-200. Fifty grams of raw material was placed on the vibratory system using power level 5 for $15 \mathrm{~min}$. The process was repeated ten times $(n=10)$. The geometric mean particle diameter was calculated according to ASAE Standards (ASAE 2008).

The moisture and lipids content of lees were determined according to the official methods published by the Association of Official Analytical Chemists (AOAC International 1997). The true density was determined by helium pycnometry (Micrometrics, model AccuPyc II 1340 V1.02, Norcross, USA) at the Central Analytical Laboratory of the Institute of Chemistry/UNICAMP, Campinas, Brazil. The bed apparent density was calculated by the ratio between the lees mass and its volume within the extraction vessel. The bed porosity was determined by the subtraction of one and the ratio between the true density and apparent density. The raw material characterization data are presented in Table 2.

\section{Extraction}

\section{Supercritical fluid extraction}

Raw material with particle size above 0.18 was used to avoid the clogging of equipment tubing. Inside of a nylon cell, the extraction bed comprised of $15 \mathrm{~g}$ of lees was formed between two thin beds of glass wool that were used as extra filters. The volume of the nylon cell was completed with glass balls with diameter of $0.5 \mathrm{~cm}$ which were placed at the top of the nylon cell. Finally, a Teflon column was used to complete the extraction vessel volume of $415 \mathrm{~cm}^{3}$. The apparent density of the extraction bed was kept constant at $367 \pm 1 \mathrm{~kg} / \mathrm{m}^{3}$. The supercritical fluid extraction was conducted in a homemade SFE system which is described in a previous work (Farias-Campomanes et al. 2013). The extraction solvent was composed by $90 \%$ of supercritical carbon dioxide and $10 \%(\mathrm{w} / \mathrm{w})$ of ethanol of $96 \%$ purity. Before dynamic extraction, the static extraction time of 10 min was considered. The parameters of the overall extraction curves (OECs) are shown in Table 3. The OECs were determined in duplicate.

The extracts were collected in amber glass flasks immersed in ice bath at atmospheric pressure, in time intervals of 10 and $30 \mathrm{~min}$. At the end of the extraction, the equipment tubing was rinsed with ethanol to recover the residual extract. The residual extracts were collected in different flasks and they were considered in the calculation of the global yield. Ethanol was separated from the extracts by vacuum evaporation in a rotary evaporator (Laborota, model 4001, Viertrieb, Germany). The thermostatic bath was kept at $313 \mathrm{~K}$. The extract mass was determined in an analytical balance (Sartorius, model A200S, Göttingen, Germany). The global yield was calculated as the percentage of the extract mass obtained from the raw material (dry basis) that was used to form the extraction bed. Yield was calculated along the OECs.

Table 1 Chemicals information

\begin{tabular}{|c|c|}
\hline Chemical & Supplier \\
\hline Acetic acid, ethanol (99.5 \%) & Ecibra (Sao Paulo, Brazil) \\
\hline Hexane & Synth (Diadema, Brazil) \\
\hline Chloroform, ethyl acetate, silica plates & Merck (Darmstadt, Germany) \\
\hline 2-Aminoethyl-diphenylborinate (NP), 2,2-diphenyl-1-picrylhydrazyl (DPPH), p-anisaldehyde & Sigma Aldrich (Saint Louis, USA) \\
\hline \multicolumn{2}{|c|}{$\begin{array}{l}\text { Standards (purity >90 \%): gallic acid protocatechuic acid, p-hydroxybenzoic acid, syringic acid, } p \text {-coumaric acid, ferulic } \\
\text { acid, quercetin, rutin, catechin, resveratrol }\end{array}$} \\
\hline HPLC grade: acetonitrile, methanol & Tedia (Rio de Janeiro, Brazil) \\
\hline
\end{tabular}


Table 2 Raw material characterization data

\begin{tabular}{|c|c|c|}
\hline \multirow[t]{2}{*}{ Particle size distribution } & \multirow[t]{2}{*}{ Pore diameter $(\mathrm{mm})$} & \multirow{2}{*}{$\begin{array}{l}\text { Value } \\
\text { Raw material retained (\%) }\end{array}$} \\
\hline & & \\
\hline \multicolumn{3}{|l|}{ Series Tyler (mesh) } \\
\hline- & $<0.074$ & $11 \pm 2$ \\
\hline 200 & 0.074 & $22 \pm 4$ \\
\hline 100 & 0.15 & $28 \pm 5$ \\
\hline 80 & 0.18 & $11 \pm 3$ \\
\hline 48 & 0.30 & $15 \pm 6$ \\
\hline 32 & 0.50 & $5 \pm 1$ \\
\hline 24 & 0.71 & $4 \pm 1$ \\
\hline \multirow[t]{2}{*}{16} & 1.00 & $4 \pm 2$ \\
\hline & Total & 100 \\
\hline Geometric mean diameter of the particle $(\mathrm{mm})$ & & $0.18 \pm 0.01$ \\
\hline Moisture (\%) & & $12.3 \pm 0.2$ \\
\hline Lipids (\%) & & $1.43 \pm 0.04$ \\
\hline True density $\left(\mathrm{kg} / \mathrm{m}^{3}\right)$ & & $1631 \pm 1$ \\
\hline Bed apparent density $\left(\mathrm{kg} / \mathrm{m}^{3}\right)$ & & $367 \pm 1$ \\
\hline Bed porosity & & $0.775 \pm 0.002$ \\
\hline
\end{tabular}

Table 3 Parameters of the overall extraction curves performed at $313 \mathrm{~K}$

\begin{tabular}{|c|c|c|c|c|}
\hline Pressure (MPa) & $\begin{array}{l}\text { Dynamic extraction } \\
\text { time }(\mathrm{h})\end{array}$ & $\begin{array}{l}\text { Flow rate of } \mathrm{CO}_{2} \\
\left(10^{-5} \mathrm{~kg} / \mathrm{s}\right)\end{array}$ & $\begin{array}{l}\text { Flow rate of } \\
\text { ethanol }\left(10^{-5} \mathrm{~kg} / \mathrm{s}\right)\end{array}$ & $\begin{array}{l}\text { Total flow rate of } \\
\text { solvent }\left(10^{-5} \mathrm{~kg} / \mathrm{s}\right)\end{array}$ \\
\hline \multirow[t]{2}{*}{20} & 8 & $11.3 \pm 0.1$ & 1.25 & $12.6 \pm 0.1$ \\
\hline & 8 & $11.4 \pm 0.1$ & 1.26 & $12.7 \pm 0.1$ \\
\hline \multirow[t]{2}{*}{35} & 8 & $11.3 \pm 0.1$ & 1.25 & $12.6 \pm 0.1$ \\
\hline & 6 & $8.6 \pm 0.5$ & 0.95 & $9.6 \pm 0.5$ \\
\hline
\end{tabular}

\section{Modeling of overall extraction curves}

Experimental data were fitted into a spline of three lines, where the first line indicates the constant extraction rate period (CER), the second one the falling extraction rate period (FER) and the third one the diffusion-controlled period (DC) (Meireles 2007). The procedures PROC REG and PROC NLIN of the software SAS (SAS Institute Inc. Version v9.2, Cary, USA) were used to fit the OECs. From the spline, the kinetic parameters for the CER period: the duration of the process $\left(t_{\mathrm{CER}}\right)$, the mass transfer rate $\left(M_{\mathrm{CER}}\right)$, the solute mass ratio in the supercritical phase at the exit of the extractor $\left(Y_{\mathrm{CER}}\right)$ and the global yield relative to CER period $\left(R_{\mathrm{CER}}\right)$ were estimated (Meireles 2007).

\section{Conventional extractions}

Conventional extraction techniques such as soxhlet and agitated bed extraction were performed to compare them with the SFE. Soxhlet was conducted using $160 \mathrm{~g}$ of ethanol (96\% purity) as extraction solvent and $8 \mathrm{~g}$ of lees with geometric mean diameter of the particle of $0.18 \pm 0.01 \mathrm{~mm}$, as raw material. Soxhlet extraction was performed for $3 \mathrm{~h}$ and the extraction time was determined according to preliminary assays, in which the global yield was increased and the same polyphenol profile was unchanged when the extraction time was increased from 2 to $3 \mathrm{~h}$. The experiments were performed in duplicate. Agitated bed extraction was carried out by placing $3 \mathrm{~g}$ of lees with $30 \mathrm{~g}$ of ethanol (96\%) into $250 \mathrm{ml}$ erlenmeyer flasks. The extractions were conducted in a shaker (Marconi, model MA420, Piracicaba, Brazil) at $313 \mathrm{~K}$ and agitation of $168 \mathrm{rpm}$. Extract samples were collected every $30 \mathrm{~min}$ for $6 \mathrm{~h}$. After that the process was completed, the extracts were filtered using filter paper. Ethanol from extracts obtained by soxhlet and agitated bed extraction was removed by vacuum evaporation at $313 \mathrm{~K}$ and $0.01 \mathrm{MPa}$; the extract masses were weighed and global yield was calculated.

\section{Analyses of the extracts Thin-layer chromatography}

The extracts were analyzed by thin-layer chromatography (TLC) according to the method for polyphenols (Wagner 
and Blad 1996). The extracts were diluted in ethanol $(15 \mathrm{mg} / \mathrm{ml})$ and the standards (gallic acid, quercetin and rutin) were diluted in methanol $(0.3 \mathrm{mg} / \mathrm{ml})$.

Two mobile phases were studied: the mixture of ethyl acetate and chloroform $(91: 9, \mathrm{v} / \mathrm{v})(\mathrm{A})$ and the mixture of hexane and ethyl acetate (70:30, v/v) (B). Silica plates of $20 \mathrm{~cm} \times 20 \mathrm{~cm}$ and $1 \mathrm{~mm}$ of thick were used for the chromatographic separations. The plates were examined under visible light and UV lamp (254 and $366 \mathrm{~nm}$ ). Revelation of the polyphenols was performed by spraying solutions of 2-aminoethyl-diphenylborinate (NP), 2,2-diphenyl-1-picrylhydrazyl (DPPH) and $p$-anisaldehyde (AS).

\section{High-performance liquid chromatography}

HPLC analysis of polyphenols was conducted on the Dionex 3000 Ultimate system (Sunnyvale, USA) equipped with a diode array detector (Ultimate 3000, DAD-3000). The temperature of the samples was kept at $283 \mathrm{~K}$. Poroshell C18 column $(100 \times 4.6 \mathrm{~mm}, 2.6 \mu \mathrm{m}$, Agilent Technologies, USA), heated at $323 \mathrm{~K}$, was used for the chromatographic separation. The separation method developed by Rostagno et al. (2011) was used. The mobile phases were water containing $0.1 \%$ of acetic acid (A) and acetonitrile containing $0.1 \%$ of acetic acid (B) and its composition varied over a linear gradient from 0 to $100 \% \mathrm{~B}$ in $15 \mathrm{~min}$. Equilibration time of $3 \mathrm{~min}$ was considered. The flow rate was $2 \mathrm{ml} / \mathrm{min}$ and the injection volume was $10 \mu$ l. Polyphenols were detected at different wavelengths: $254 \mathrm{~nm}$ for gallic, protocatechuic, $p$-hydroxybenzoic acids as well as quercetin, $280 \mathrm{~nm}$ for syringic acid and catechin, $305 \mathrm{~nm}$ for resveratrol and $320 \mathrm{~nm}$ for $p$-coumaric and ferulic acids. Polyphenols identification was performed by the comparison of UV spectra and retention times of polyphenols in the extracts with those obtained for the standards. The quantification of polyphenols in the extracts was performed by preparation of calibration curves. The unidentified compounds were quantified and labeled as derivatives of polyphenol standards with similar UV spectra. All determinations were performed in duplicate.

\section{Results and discussion \\ Extraction}

Freeze-dried lees can be described as weak structures formed by the agglomeration of small particles which can be disassembled by the pressure application while the extraction bed is formed. Therefore, to avoid the clogging of system tubing by small particles, the extraction bed was carefully formed by the addition of small amounts of lees without applying pressure. This procedure was adopted for all experiments.
The effect of the flow rate on the extraction was observed for the SFE experiments performed at $35 \mathrm{MPa}$. After $6 \mathrm{~h}$ of extraction, the global yield increased from 5.73 to $6.47 \%$ with the increasing of the total flow rate from $9.6 \pm 0.5 \times 10^{-5}$ to $12.6 \pm 0.1 \times 10^{-5} \mathrm{~kg}$ $\mathrm{CO}_{2}+$ ethanol/s. According to Kumoro and Hasan (2007), the solvent flow rate is related to the mass transfer resistance and thermodynamic equilibrium. When low flow rate is used, the mass transfer resistance limits the amount of extract that is dissolved in the solvent; as a consequence, the solvent leaves the extraction vessel unsaturated. The increasing of the flow rate increases the amount of solvent passing through the raw material per unit of time and decreases the mass transfer resistance allowing the saturation of the solvent. When solvent is saturated of extract, the thermodynamic equilibrium is achieved and the global yield is the highest possible. However, increasing of the flow rate not always improves the efficiency of the process. High flow rate decreases the residence time of solvent inside the extraction vessel, then, the system exits from thermodynamic equilibrium and, consequently, the solvent leaves the extractor unsaturated. In that sense, higher extraction flow rates must be studied for the carbon dioxide-ethanol-lees system to determine the flow rate in which the thermodynamic equilibrium is achieved.

The effect of the solvent flow rate on the extraction yield can be neglected by representing the global yield as a function of solvent mass to feed mass ratio $(S / F)$ instead of time, as is shown in Fig. 1. The extraction time and $S / F$ ratios were not high enough to depletion of the extract in the solid matrix. As result of the reproducibility of the experiments, similar global yields were obtained for experiments performed at the same pressure and temperature and constant $S / F$ ratio.

Usually, at constant temperature, the increase of pressure increases the solvation power of the solvent; consequently, more compounds are dissolved and the global yield is increased (Kumoro and Hasan 2007; Mukhopadhyay 2000). However, in this study, at $313 \mathrm{~K}$, the increasing of pressure from 20 to $35 \mathrm{MPa}$ decreased the global yield from $10.5 \pm 0.2$ to $7.6 \%$ in dry basis. This opposite effect can be attributed to the decreasing of the diffusion coefficient of the solvent, caused by increase of density.

Also, the decreasing of the global yield when pressure increases can be related to the porosity of the extraction bed comprised by lees. Porous extraction beds as those comprised by macela leaves (Takeuchi 2009), and grape bagasse (Farias-Campomanes 2012) experimented an irregular compaction with presence of preferential paths when pressure was increased. Preferential paths inside the solid matrix reduce the contact between the solvent 


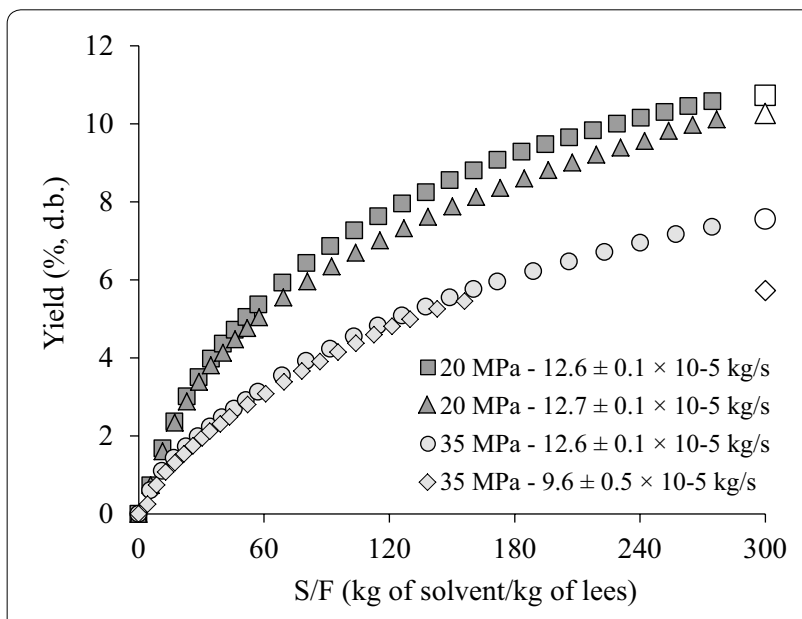

Fig. 1 Overall extraction curves performed at 20 and $35 \mathrm{MPa}, 313 \mathrm{~K}$. White markers correspond to the residual extracts

and the raw material, promoting a partial extraction with low global yields.

The highest global yield of SFE of lees from pisco-making was $10.5 \pm 0.2 \%$ in dry basis, and was obtained at $313 \mathrm{~K} / 20 \mathrm{MPa}$. The global yield of lees of pisco-making is higher than those reported for grape bagasse from piscomaking: $5.5 \pm 0.1$ and $5.6 \%$ for 20 and $35 \mathrm{MPa}$, respectively (Farias-Campomanes et al. 2013); and for lees from wine rice: $5.4 \%$ (Jia-Jiuan et al. 2009).

Conventional techniques also have been applied for extracting polyphenols from lees recovered from other processes. Mena et al. (2014) studied the agitation followed by ultrasound extraction from pomegranate lees and reported global yield of $51 \mathrm{~g}$ of centrifuged and lyophilized extract per liter of lees. Jia-Jiuan et al. (2009) concluded that soxhlet, using ethanol (95\% of purity) as the extraction solvent, provides low global yields and extracts with high polyphenols content from rice wine lees.

In this work, the global yields of the conventional extraction techniques (soxhlet and agitated bed) were higher than those obtained by SFE: $27.6 \pm 0.4$ and $16.8 \pm 0.2 \%$, respectively. This was expected since the use of high temperature and long extraction times in the soxhlet and agitated bed extraction, respectively, cause a reduction of the extraction selectivity and favor the co-extraction of undesirable compounds. No significant difference between global yields obtained throughout kinetic extraction of agitated bed extraction was observed.

\section{Modeling}

The overall extraction curves were fitted to three straight lines. The first line indicates the constant extraction rate
(CER) period, where the main mass transfer mechanism is convection in the fluid phase. The second one indicates the falling extraction rate (FER) period, where the transfer mass resistance increases. In FER period, the mass transfer mechanisms are the convection in the fluid phase and diffusion in the solid phase due to the extract depletion on its surface. The third one indicates the diffusion-controlled (DC) period, where the extraction occurs mainly by diffusion inside the solid particle (Fig. 2). The duration of CER period $\left(t_{\mathrm{CER}}\right)$, determined by the intersection of the first and second lines, represents the minimum time a SFE batch should last (Meireles 2007). For the overall extraction curves performed at 20 and $35 \mathrm{MPa}$, the estimated $t_{\text {CER }}$ were 0.9 and $0.7 \mathrm{~h}$, respectively. The kinetics parameters of the OECs performed at 20 and $35 \mathrm{MPa}$, $313 \mathrm{~K}$ and total flow rate of $12.6 \pm 0.1 \mathrm{~kg} / \mathrm{s}$ are shown in Table 4. At $20 \mathrm{MPa}$, the relative yield to the CER period $\left(R_{\mathrm{CER}}\right)$ was equivalent to $37 \%$ of the global yield, while at $35 \mathrm{MPa}, R_{\mathrm{CER}}$ was equivalent to $18 \%$ of the highest global

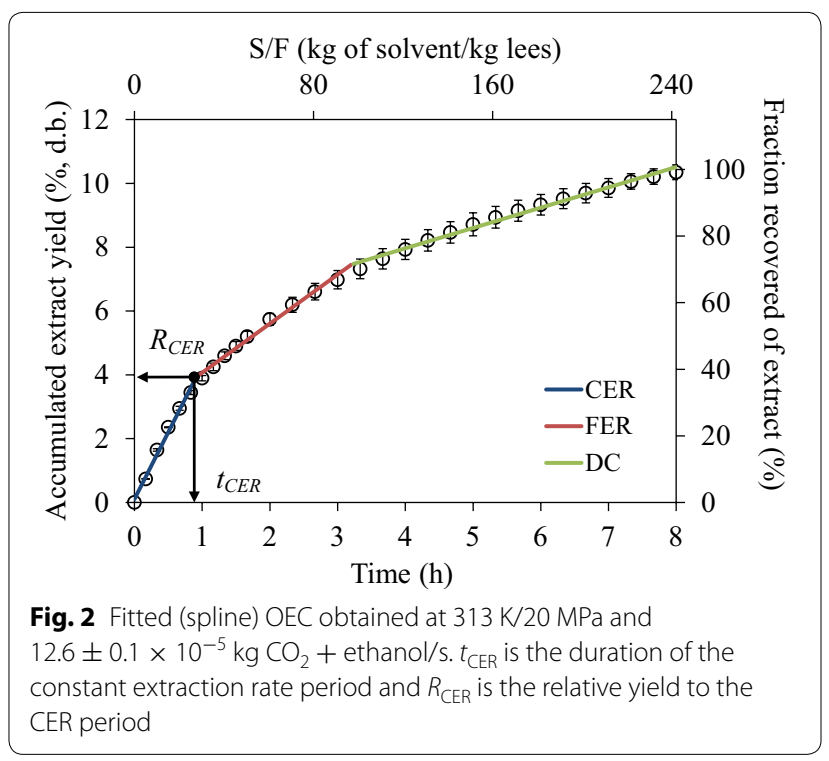

Table 4 Kinetic parameters for SFE of lees from pisco-making

\begin{tabular}{lcc}
\hline Parameter & $\mathbf{2 0 ~} \mathbf{~ P P a}$ & 35 $\mathbf{~ M a a}$ \\
\hline$t_{\text {CER }}(\mathrm{h})$ & $0.90 \pm 0.01$ & $0.71 \pm 0.01$ \\
$t_{\text {FER }}(\mathrm{h})$ & $3.22 \pm 0.03$ & $3.2 \pm 0.1$ \\
$M_{\mathrm{CER}}\left(10^{-8} \mathrm{~kg}\right.$ extract/s) & $16 \pm 2$ & $10 \pm 1$ \\
$Y_{\text {CER }}\left(10^{-4} \mathrm{~kg}\right.$ extract/kg solvent $)$ & $12.5 \pm 0.1$ & $8.0 \pm 0.3$ \\
$R_{\text {CER }}(\%$, d.b. $)$ & $3.9 \pm 0.4$ & $1.9 \pm 0.2$ \\
$R_{\text {TOTAL }}(\%$, d.b. $)$ & $10.5 \pm 0.4$ & $7.5 \pm 0.2$ \\
\hline
\end{tabular}

$t_{C E R}$ duration of the constant extraction rate (CER) period, $t_{F E R}$ duration of the falling extraction rate (FER) period, $M_{C E R}$ mass transfer rate at $t_{C E R}, Y_{C E R}$ solute mass ratio in the supercritical phase at the exit of the extractor at $t_{C E R}, R_{C E R}$ extraction yield at $t_{\text {CER, }} R_{\text {TOTAL }}$ global yield of the process 
yield (SFE at $20 \mathrm{MPa}$ ). In addition, the mass transfer rate $\left(M_{\mathrm{CER}}\right)$ and the mass ratio of extract in the supercritical phase at the bed outlet $\left(Y_{\mathrm{CER}}\right)$, relative to CER period, decreased approximately $40 \%$ when the pressure was increased from 20 to $35 \mathrm{MPa}$. From the results, since SFE at $313 \mathrm{~K} / 20 \mathrm{MPa}$ showed the best extraction performance, then, the minimum duration of the SFE batch was estimated in $0.9 \mathrm{~h}$.

\section{Composition of the extracts}

According to Wagner and Blad (1996), flavonoids aglycones are fluorescents, flavonoid glycosides are usually red-orange and carboxylic acids are blue when examined with a UV lamp at $366 \mathrm{~nm}$. At the same wavelength, SFE extracts obtained at 20 and $35 \mathrm{MPa}$ showed two fluorescent bands, two blue bands, seven red-orange bands and one dark band indicating the presence of flavonoids and carboxylic acids in the extracts (Fig. 3). Quercetin was observed using UV lamp at $254 \mathrm{~nm}$, while gallic acid and rutin were not detected in the SFE extracts. In general, SFE extracts showed the same polyphenols profile throughout the OECs.

In visible light, five yellow bands were observed throughout the OECs and were more intense for SFE extracts obtained at 35 than $20 \mathrm{MPa}$. Yellow bands in visible light suggest the presence of carotenoids (Wagner and Blad 1996). In addition, SFE extracts of the extraction periods from 80 to $480 \mathrm{~min}$ for $20 \mathrm{MPa}$ and $180-480 \mathrm{~min}$ for $35 \mathrm{MPa}$ reacted more intensively to a sprayed DPPH solution, proving the antioxidant activity of the extracts (Yang et al. 2014). SFE extracts showed green, brown, violet-blue and red bands when sprayed with anisaldehyde solution, indicating the presence of terpenoids in its composition (Wagner and Blad 1996).
In UV lamp at $366 \mathrm{~nm}$, the extracts produced by conventional techniques: soxhlet and agitated bed, showed seven bands (two blues, four red-oranges, and one yellow bands) and six bands (one blue, three red-oranges, one fluorescent and one yellow bands), respectively (Fig. 4).

Quercetin was identified in the extracts obtained by soxhlet and agitated bed extraction while rutin and gallic acid were not. The results also suggested the presence of flavonoids and carboxylic acids in the extracts obtained by conventional techniques as in the SFE extracts. Polyphenol profile of agitated bed extracts also followed the trend observed for the SFE extracts and remained constant throughout the kinetic extraction.

In Table 5, the identified polyphenols in the lees extracts by HPLC are shown. Ten polyphenols were determined, where at least four of them were identified as gallic acid, protocatechuic acid, syringic acid and quercetin. The UV spectra and relative retention time of one of the unidentified compounds matched to vanillic acid, which is widely reported as one of the major compounds in grape extracts (Shi et al. 2003; Oliveira 2010).

Moreover, five unidentified polyphenols showed similar UV spectra to $p$-coumaric acid, ferulic acid and quercetin and therefore were analyzed as derivatives of these polyphenols and expressed as equivalents of the polyphenols with the same UV spectra. These compounds were identified as $p$-coumaric derivative, ferulic acid derivative I, ferulic acid derivative II, quercetin derivative I and quercetin derivative II.

The polyphenol profile of the lees extracts obtained by SFE and conventional extraction techniques are presented in Table 5. The major polyphenols present in the SFE lees extracts were vanillic acid, syringic acid,

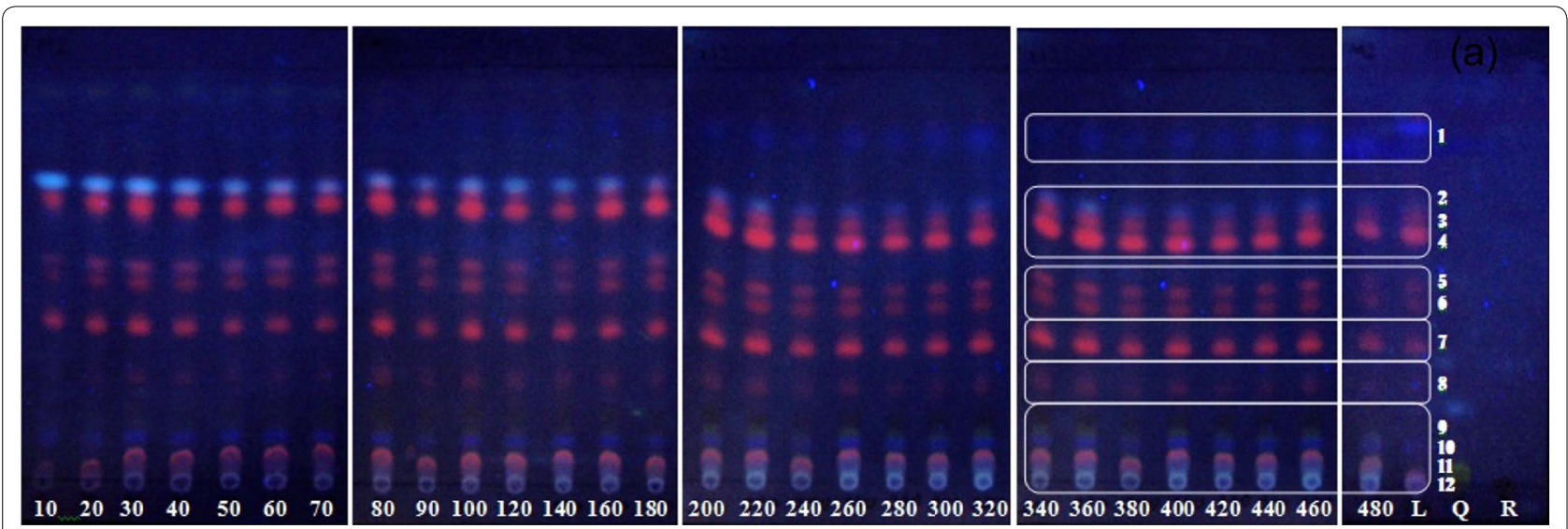

Fig. 3 Thin-layer chromatography of the SFE lees extracts obtained at $313 \mathrm{~K} / 20 \mathrm{MPa}$. Plates are shown under a UV light of wavelength $366 \mathrm{~nm}$. The $X$ axis indicates the extraction time and $Y$ axis the number of the identified bands 


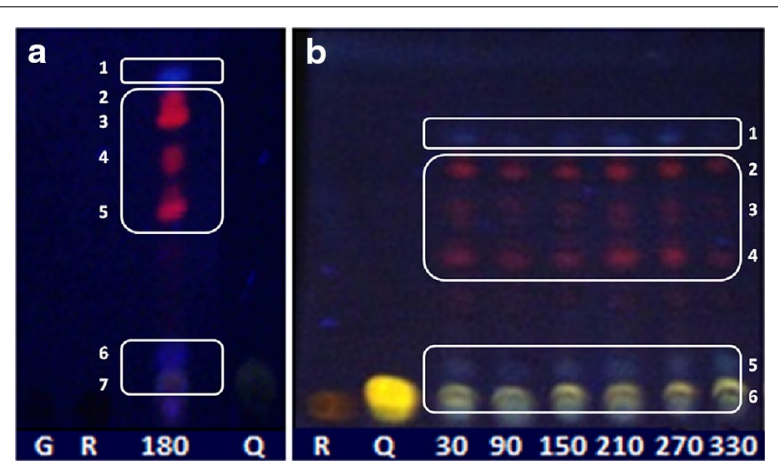

Fig. 4 Thin-layer chromatography of the extracts obtained by soxhlet (a) and agitated bed (b) extraction. Plates are shown under a UV light of wavelength $366 \mathrm{~nm}$. The $X$ axis indicates the extraction time and $Y$ axis indicates the number of the identified bands $p$-coumaric acid derivative and ferulic acid derivative I, while gallic acid, protocatechuic acid, ferulic acid derivative II, quercetin and quercetin derivative II were found in lower concentration. $p$-Coumaric acid and ferulic acid derivative II were identified only in the SFE extracts. In contrast, quercetin derivative I was only identified in the extracts obtained by soxhlet and agitated bed extraction. Resveratrol, catechin, ferulic acid, $p$-coumaric acid and $p$-hydroxybenzoic acid were not identified in the lees extracts obtained by SFE and conventional extraction techniques.

The composition of polyphenols of the extracts from lees of the pisco-making was similar to those reported for extracts from lees of wine-making (Pérez-Serradilla and Luque de Castro 2011; Alonso et al. 2002). This was expected, since the wine and pisco are made from grapes,

Table 5 Extraction conditions and extracted polyphenols from lees of pisco-making

\begin{tabular}{|c|c|c|c|c|c|}
\hline & & \multicolumn{4}{|l|}{ Extraction methods } \\
\hline & & \multicolumn{2}{|l|}{ SFE } & \multirow{2}{*}{$\begin{array}{l}\text { Agitated bed } \\
0.1\end{array}$} & \multirow{2}{*}{$\begin{array}{l}\text { Soxhlet } \\
0.1\end{array}$} \\
\hline \multicolumn{2}{|c|}{ Pressure (MPa) } & 20 & 35 & & \\
\hline \multicolumn{2}{|c|}{ Temperature (K) } & 313 & 313 & 313 & 352 \\
\hline \multicolumn{2}{|c|}{ Solvent } & $\mathrm{CO}_{2}+$ ethanol & $\mathrm{CO}_{2}+$ ethanol & Ethanol & Ethanol \\
\hline \multicolumn{2}{|c|}{ Total S/F (d.b.) } & $242 \pm 1$ & 137 & 10 & 20 \\
\hline \multicolumn{2}{|c|}{ Global yield (g/100 g of lees in dry basis) } & $10.5 \pm 0.2$ & 5.73 & $16.8 \pm 0.2$ & $27.6 \pm 0.4$ \\
\hline & \multicolumn{5}{|c|}{ Extracted polyphenols (mg/kg of lees) } \\
\hline \multicolumn{6}{|c|}{ Phenolic acids } \\
\hline 1 & Gallic acid & $7.37 \pm 0.03$ & $3.017 \pm 0.003$ & $78 \pm 4$ & $112 \pm 13$ \\
\hline 2 & Protocatechuic acid & $12.1 \pm 0.1$ & $4.56 \pm 0.04$ & $27 \pm 2$ & $40 \pm 4$ \\
\hline 3 & p-Hydroxybenzoic acid & n.d. & n.d. & n.d. & n.d. \\
\hline 4 & Vanillic acid & $61.8 \pm 0.2$ & $25.7 \pm 0.4$ & $76 \pm 3$ & $104 \pm 14$ \\
\hline 5 & Syringic acid & $59.3 \pm 0.1$ & $23 \pm 1$ & $87 \pm 2$ & $118 \pm 12$ \\
\hline 6 & p-Coumaric acid & n.d. & n.d. & n.d. & n.d. \\
\hline 7 & p-Coumaric acid derivative ${ }^{a}$ & $53.0 \pm 0.1$ & $44.6 \pm 0.1$ & n.d. & n.d. \\
\hline 8 & Ferulic acid & n.d. & n.d. & n.d. & n.d. \\
\hline 9 & Ferulic acid derivative $\mathrm{I}^{\mathrm{b}}$ & $53.25 \pm 0.01$ & $31.1 \pm 0.1$ & $41 \pm 1$ & $54 \pm 5$ \\
\hline 10 & Ferulic acid derivative $\|^{b}$ & $2.5 \pm 0.1$ & $2.78 \pm 0.02$ & n.d. & n.d. \\
\hline \multicolumn{6}{|c|}{ Flavonoids } \\
\hline 11 & Quercetin & $15.6 \pm 0.1$ & $5.8 \pm 0.1$ & $121 \pm 2$ & $183 \pm 22$ \\
\hline 12 & Quercetin derivative $I^{\complement}$ & n.d. & n.d. & $24.6 \pm 0.5$ & $40 \pm 6$ \\
\hline 13 & Quercetin derivative $\|^{c}$ & $8.7 \pm 0.1$ & $3.40 \pm 0.01$ & n.d. & $30 \pm 3$ \\
\hline 14 & Catechin & n.d. & n.d. & n.d. & n.d. \\
\hline \multicolumn{6}{|c|}{ Stilbenes } \\
\hline \multirow[t]{2}{*}{15} & Resveratrol & n.d. & n.d. & n.d. & n.d. \\
\hline & Total extracted polyphenols & $274 \pm 1$ & $144 \pm 1$ & $455 \pm 15$ & $682 \pm 80$ \\
\hline
\end{tabular}

\footnotetext{
a Expressed as milligrams of $p$-coumaric acid equivalents

b Expressed as milligrams of ferulic acid equivalents

c Expressed as milligrams of quercetin equivalents
} 
however, using different processing conditions and varieties of grapes. Quercetin, quercetin-3-O-glucoside, quercetin-3-O-glucuronide, quercetin-3- $\beta$-glucoside, $p$-coumaric acid, $p$-coumaroyl derivatives, vanillic acid, syringic acid and ferulic acid were some of the detected polyphenols in the extracts from lees of wine-making; which could match with the unidentified polyphenols in the extracts from lees of pisco-making. In general, despite the use of large amounts of solvent for a long period of time by the SFE processes, the highest values of extracted polyphenols were obtained by the conventional techniques: $455 \pm 15 \mathrm{mg} / \mathrm{kg}$ of lees by agitated bed extraction and $682 \pm 80 \mathrm{mg} / \mathrm{kg}$ of lees by soxhlet (Table 5 ).

Due to the low polarity of carbon dioxide, SFE was more efficient on the extraction of the less polar polyphenols. Also, the best polyphenols extraction performance was observed at $20 \mathrm{MPa}$.

Figure 5 shows the overall extraction curves and the concentration in the extracts, of the less polar polyphenols obtained by SFE. Vanillic acid, syringic acid and ferulic acid derivative I were constantly solvated by carbon dioxide and ethanol along the OECs performed at 20 and $35 \mathrm{MPa}$ (green dots). However, at $20 \mathrm{MPa}$, the concentration of these polyphenols in the extracts (white dots) was kept approximately constant from $2 \mathrm{~h}$ (onward); in contrast, at $35 \mathrm{MPa}$ the concentration in the extracts increased along the OEC. The results suggest that after $6 \mathrm{~h}$ of extraction at $35 \mathrm{MPa}$, the extraction process of vanillic acid, syringic acid and ferulic acid derivative $\mathrm{I}$ is still in the initial stage, where the highest yields are obtained; while at $20 \mathrm{MPa}$ and $2 \mathrm{~h}$ of extraction, the extraction process of these less polar polyphenols continues but with the solvation of other polyphenols which are in greater quantities in the collected extracts along the OECs. In both cases, the positive gradients of the overall extraction curves of the less polar polyphenols indicate that longer time to complete the extraction is required.

On the other side, $p$-coumaric acid and ferulic acid derivative II were almost completely extracted at the beginning of the $\mathrm{OEC}$ at $20 \mathrm{MPa}$; hence, its concentration in the extracts decreased along the OEC (Fig. 5). In contrast, due to the SFE at $35 \mathrm{MPa}$ showed lower mass transfer rate than $20 \mathrm{MPa}$; then, the extraction of $p$-coumaric acid and ferulic acid derivative II from lees continues along the OEC.

Figure 6 shows the OECs of the more polar polyphenols: gallic acid, protocatechuic acid, quercetin and quercetin derivative II, and its concentration in the extracts along the OECs. The more polar polyphenols were constantly extracted along the OECs performed at 20 and $35 \mathrm{MPa}$ (red dots) and its concentration in the extracts increased with the extraction time (white dots).
In contrast, for the less polar polyphenols, the extraction of the more polar polyphenols did not start together with the extraction process, since they were not identified in the extracts collected in the extraction period of 0-10 min (20 and $35 \mathrm{MPa}$ ). Also, protocatechuic acid and quercetin were not identified in the extracts collected in the extraction period of $10-30$ and $10-40 \mathrm{~min}$ at $35 \mathrm{MPa}$.

Figure 7 shows the polyphenol total concentration of the lees extracts obtained by SFE, soxhlet and agitated bed extraction, as function of time. The concentrations of polyphenols in the extracts from lees of pisco-making obtained by SFE and conventional techniques were lower than those reported for wine lees (Yang et al. 2014; PérezSerradilla and Luque de Castro 2011). Due to the concentration of polyphenols in lees depends on the production process parameters and the initial content of polyphenols in the used grapes; then, it is not possible to conclude that the extraction techniques reviewed in this work were inefficient in the extraction of polyphenols from lees of pisco-making. In addition, it must be considered that the extracts from lees of pisco-making were analyzed mainly in terms of phenolic acids and flavonoids contents. In addition, due to the lack of the standards, anthocyanins were not determined in spite of the intense color purple of the extracts.

The maximum concentration of polyphenols in the extracts $(2796 \pm 7 \mathrm{mg} / \mathrm{kg})$ was obtained by SFE at $313 \mathrm{~K} / 20 \mathrm{MPa}$ and $4 \mathrm{~h}$ of extraction; however, extracts highly concentrated in polyphenols (2629 $\pm 17 \mathrm{mg} /$ $\mathrm{kg}$ ), equivalent to $95 \%$ of the maximum concentration of polyphenols in the extract, were obtained in $1 \mathrm{~h}\left(t_{\mathrm{CER}}\right)$ of extraction and $S / F$ ratio of 30 . In contrast, extracts with the lowest concentration of polyphenols were obtained by SFE at $313 \mathrm{~K} / 35 \mathrm{MPa}$. Figure 7 shows a continuous increasing of the polyphenol concentration in the extracts, indicating that the depletion of polyphenols from lees was not occurred and, thus, the use of higher $S / F$ ratio or longer extraction time to achieve the equilibrium was required. Soxhlet and agitated bed extraction produced extracts with intermediate concentration of polyphenols $(2123 \pm 299$ and $2095 \pm 59 \mathrm{mg} / \mathrm{kg}$ of extract, respectively), after long periods of time ( 3 and $6 \mathrm{~h}$, respectively), using large amounts of pure ethanol as extraction solvent $(S / F$ of 10 and 20, respectively).

Considering the aspects cited above, SFE extracted the lowest amount of polyphenols from lees but rapidly produced extracts with the highest concentration of polyphenols by consuming small amounts of carbon dioxide and ethanol. In addition, due to the low polarity of the carbon dioxide, extracts highly concentrated in less polar polyphenols were obtained by SFE. 


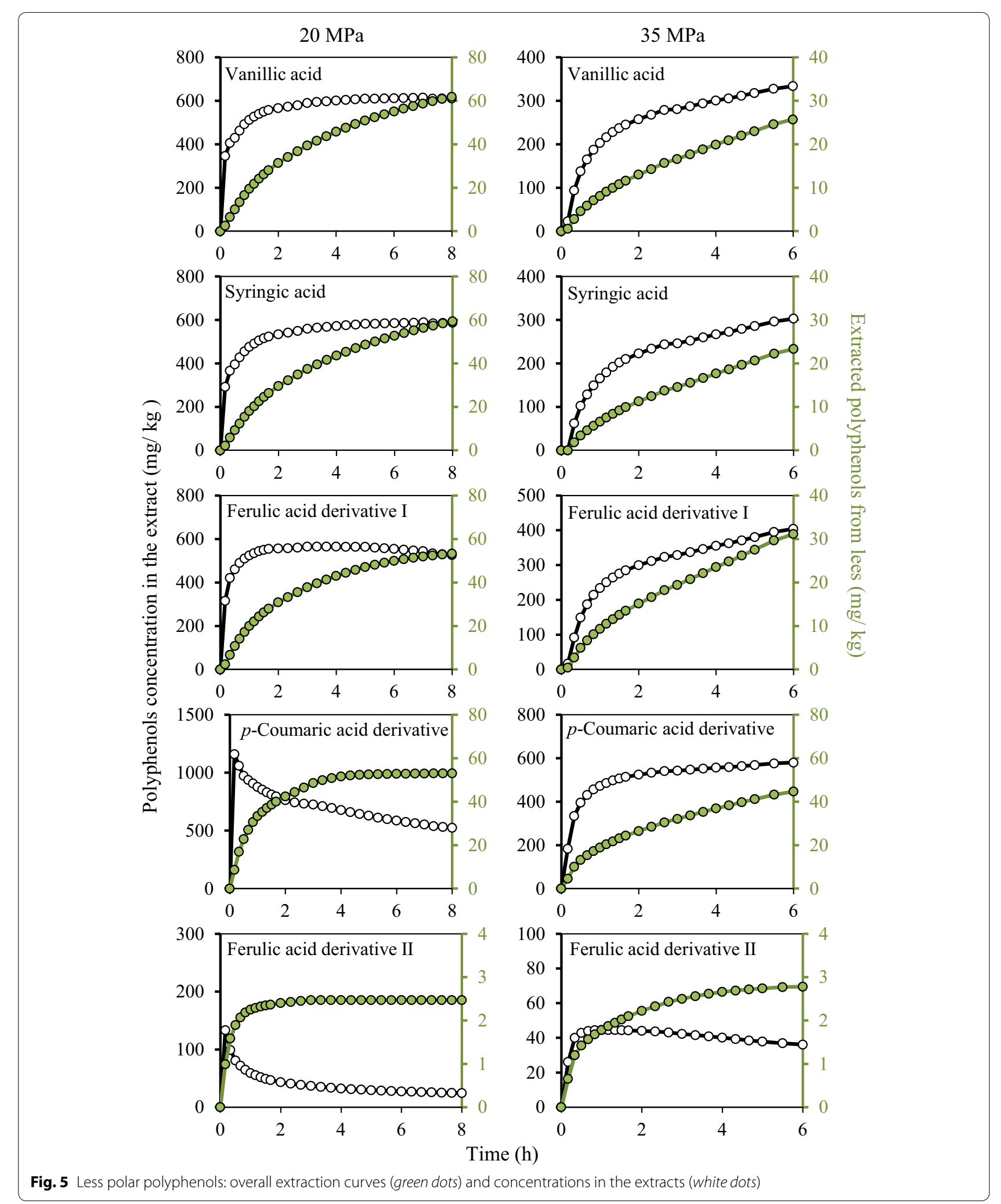




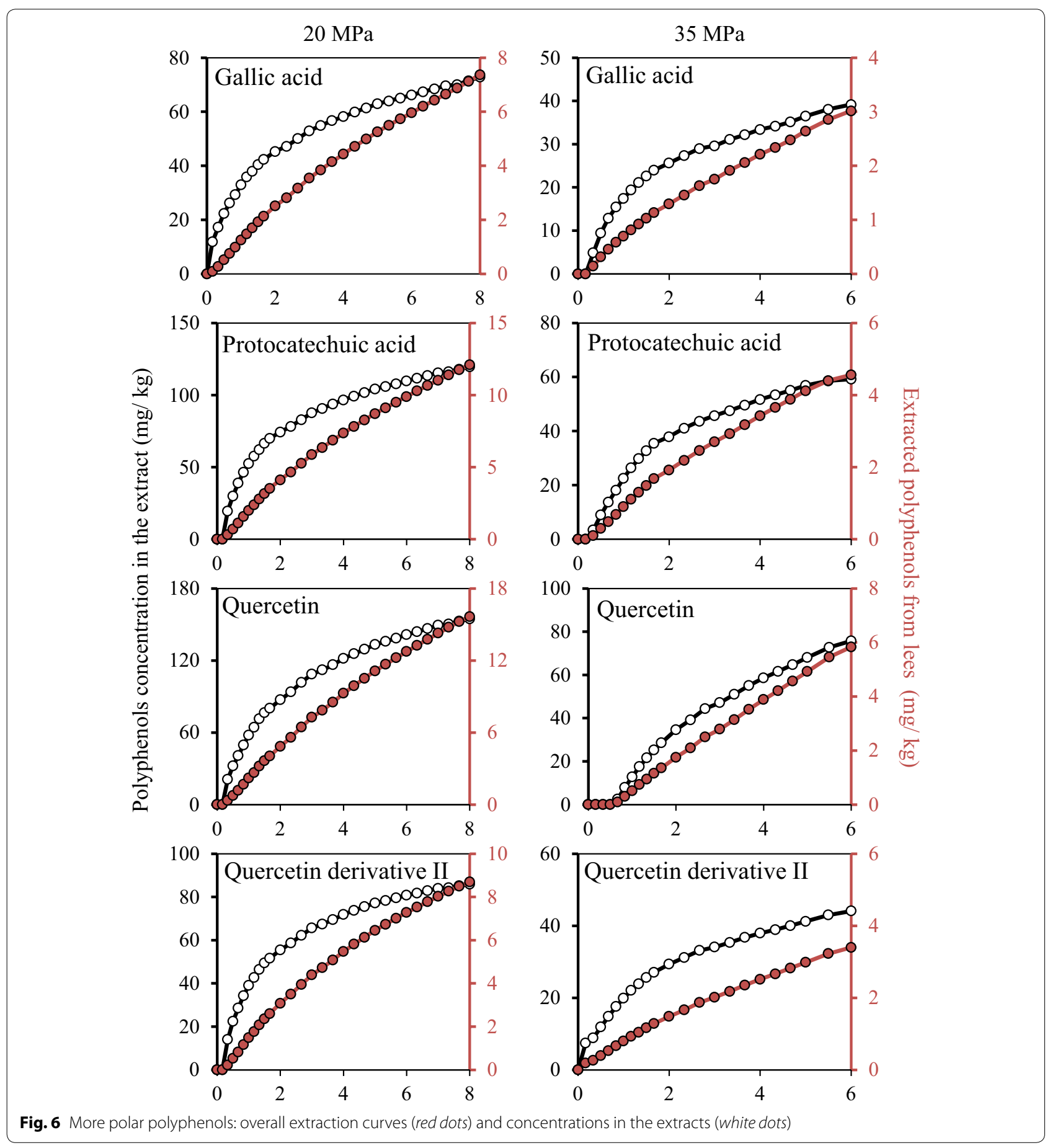

The extraction of polar polyphenols from lees of piscomaking can be improved by the increase of ethanol percentage in the extraction solvent. However, a recent green extraction technique such as the pressurized liquid extraction (PLE) of solvent accelerated extraction (ASE) could be more favorable than SFE and conventional extraction techniques for extracting bioactive compounds (Cardenas-Toro et al. 2015; Santos et al. 2012). 


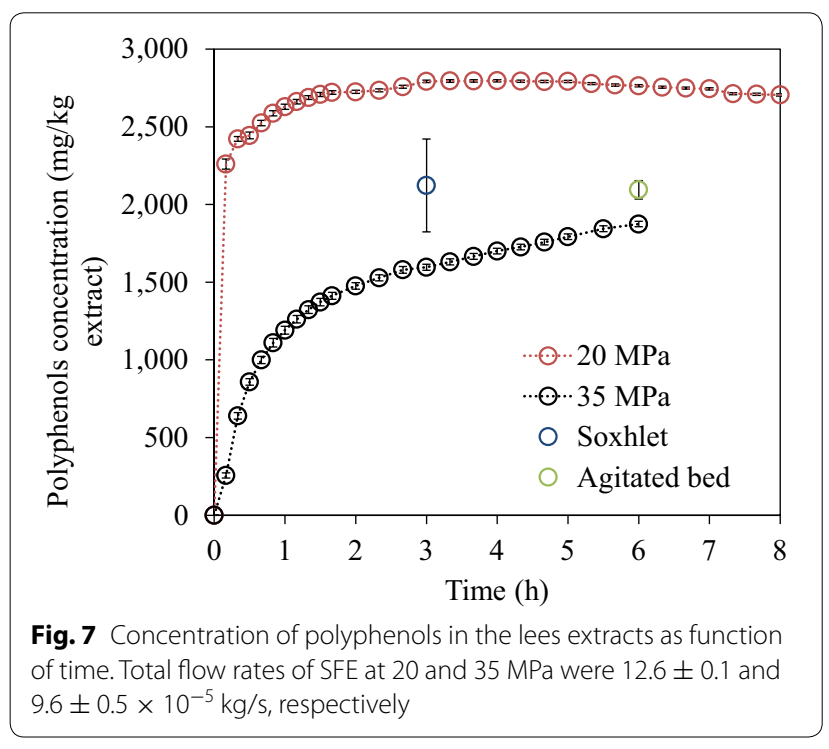

\section{Conclusions}

Lees from pisco-making are a promising source for recovery of high-value compounds such as polyphenols. In SFE, the high porosity of the extraction bed comprised by freeze-lyophilized lees can be related with the reducing of the global yield when the pressure was increased. Also, according to the estimated kinetic parameters, high mass transfer rate and high extract mass and solvent mass ratio were obtained at $313 \mathrm{~K} / 20 \mathrm{MPa}$; and the duration of the CER period was estimated in $0.9 \mathrm{~h}$. Ten polyphenols were determined in the lees extracts including phenolic acids: gallic, protocatechuic, vanillic, syringic, $p$-coumaric derivative, ferulic derivatives; and flavonoids: quercetin and quercetin derivatives. Finally, SFE at $313 \mathrm{~K} / 20 \mathrm{MPa}$ was the most efficient technique on the extraction of polyphenols from lees of pisco-making due to highly concentrated polyphenols extracts were rapidly obtained by the consumption of small amounts of solvent.

\section{Abbreviations \\ SFE: supercritical fluid extraction; OEC: overall extraction curve; S/F: solvent mass to feed mass ratio; CER: constant extraction rate period; FER: falling extraction rate period; DC: diffusion controlled.}

\section{Authors' contributions}

AMFC, MAR, JJCQ, and MAAM have contributed equally. All authors read and approved the final manuscript.

\footnotetext{
Author details

${ }^{1}$ LASEFI/DEA/School of Food Engineering (FEA), University of Campinas (UNICAMP), Rua Monteiro Lobato 80, Campinas, SP 13083-862, Brazil. ${ }^{2}$ LAPFAL/ School of Applied Science (FCA), University of Campinas (UNICAMP), Rua Pedro Zaccaria, 1300, Limeira, SP 13484-350, Brazil. ${ }^{3}$ Department of Food Engineering, School of Engineering and Architecture (FIA), Peruvian Union University (UPeU), Carretera Central Km 19.5, Ñaña, Lima, Peru.
}

\section{Acknowledgements}

The authors thank Candela winery (Lima, Peru) for providing the raw material and CNPq (190667/2010-9) and FAPESP (2009/17234-9 and 2013/04304-4) for financial support. The authors would like to acknowledge Prof. Miriam D. Hubinger for the use of the HPLC.

\section{Competing interests}

The authors declare that they have no competing interests.

Received: 16 September 2015 Accepted: 16 November 2015 Published online: 30 November 2015

\section{References}

Adil IH, Cetin HI, Yener ME, Bayindirli A (2007) Subcritical (carbon dioxide plus ethanol) extraction of polyphenols from apple and peach pomaces, and determination of the antioxidant activities of the extracts. J Supercrit Fluids 43:55-63

Alonso ÁM, Guillén DA, Barroso CG, Puertas B, García A (2002) Determination of antioxidant activity of wine byproducts and its correlation with polyphenolic content. J Agric Food Chem 50:5832-5836

AOAC International (1997) Official methods of analysis of AOAC International, vol 16. Association of Analytical Communities, Washington

ASAE (2008) Method of determining and expressing fineness of feed materials by sieving. American Society of Agricultural Engineers Standards, Michigan.

Brunner G (2005) Supercritical fluids: technology and application to food processing. J Food Eng 67:21-33

Bustamante MA, Moral R, Paredes C, Perez-Espinosa A, Moreno-Caselles J, Perez-Murcia MD (2008) Agrochemical characterisation of the solid by-products and residues from the winery and distillery industry. Waste Manag (Oxf) 28:372-380

Campos LMAS, Leimann FV, Pedrosa RC, Ferreira SRS (2008) Free radical scavenging of grape pomace extracts from Cabernet Sauvingnon (Vitis vinifera). Bioresour Technol 99:8413-8420

Cardenas-Toro FP, Alcázar-Alay SC, Coutinho JP, Godoy HT, Forster-Carneiro T, Meireles MAA (2015) Pressurized liquid extraction and low-pressure solvent extraction of carotenoids from pressed palm fiber: experimental and economical evaluation. Food Bioprod Process 94:90-100

Cardoso LC, Serrano CM, Quintero ET, Lopez CP, Antezana RM, de la Ossa EJM (2013) High pressure extraction of antioxidants from Solanum stenotomun peel. Molecules 18:3137-3151

Da Porto C, Natolino A, Decorti D (2014) Extraction of proanthocyanidins from grape marc by supercritical fluid extraction using $\mathrm{CO}_{2}$ as solvent and ethanol-water mixture as co-solvent. J Supercrit Fluids 87:59-64

Delgado Adamez J, Gamero Samino E, Valdes Sanchez E, Gonzalez-Gomez D (2012) In vitro estimation of the antibacterial activity and antioxidant capacity of aqueous extracts from grape-seeds (Vitis vinifera L.). Food Control 24:136-141

Devesa-Rey R, Vecino X, Varela-Alende JL, Barral MT, Cruz JM, Moldes AB (2011) Valorization of winery waste vs. the costs of not recycling. Waste Manag (Oxf) 31:2327-2335

Farias-Campomanes AM (2012) Recovery of bioactive compounds by supercritical and conventional extraction from grape wastes of pisco industry. Dissertation, University of Campinas, Brazil

Farias-Campomanes AM, Meireles MAA (2013) Pisco bagasse as a potential source of bioactive compounds-a review. Recent Pat Eng 7:41-50

Farias-Campomanes AM, Rostagno MA, Meireles MAA (2013) Production of polyphenol extracts from grape bagasse using supercritical fluids: yield, extract composition and economic evaluation. J Supercrit Fluids 77:70-78

García-Lafuente A, Guillamón E, Villares A, Rostagno MA, Martínez JA (2009) Flavonoids as anti-inflammatory agents: implications in cancer and cardiovascular disease. Inflamm Res 58:537-552

Içen H, Gürü M (2010) Effect of ethanol content on supercritical carbon dioxide extraction of caffeine from tea stalk and fiber wastes. J Supercrit Fluids 55:156-160 
Jia-Jiuan W, Jung-Chuan L, Chih-Hung W, Ting-Ting J, Hsing-Ling Y, Shi-Lan H, Chieh-ming JC (2009) Extraction of antioxidative compounds from wine lees using supercritical fluids and associated anti-tyrosinase activity. J Supercrit Fluids 50:33-41

Kumoro AC, Hasan M (2007) Supercritical carbon dioxide extraction of Andrographolide from Andrographis paniculata: effect of the solvent flow rate, pressure and temperature. Chin J Chem 15:877-883

Meireles MAA (2007) Extraction of Bioactive Compounds from Latin American Plants. In: Martinez JL (ed) Supercritical fluid extraction of nutraceuticals and bioactive compounds. CRC Press-Taylor and Francis Group, Boca Raton

Mena P, Ascacio-Valdés JA, Gironés-Vilaplana A, Del Rio D, Moreno DA, GarcíaViguera C (2014) Assessment of pomegranate wine lees as a valuable source for the recovery of (poly)phenolic compounds. Food Chem 145:327-334

Michels KB, Schulze MB (2005) Can dietary patterns help us detect diet-disease associations? Nutr Res Rev 18:241-248

Mukhopadhyay M (2000) Natural extracts using supercritical carbon dioxide. CRC Press, New York

Naziri E, Nenadis N, Mantzouridou FT, Tsimidou MZ (2004) Valorization of the major agrifood industrial by-products and waste from Central Macedonia (Greece) for the recovery of compounds for food applications. Food Res Int 65:350-358

Oliveira DA (2010) Phytochemical and biological characterization of the extracts obtained from grape marc (Vitis vinifera) of the varieties Merlot and Syrah. Dissertation, Federal University of Santa Catarina, Brazil

Pérez-Serradilla JA, Luque de Castro MD (2008) Role of lees in wine production: a review. Food Chem 111:447-456

Pérez-Serradilla JA, Luque de Castro MD (2011) Microwave-assisted extraction of phenolic compounds from wine lees and spray-drying of the extract. Food Chem 124:1652-1659
Prado JM, Dalmolin I, Carareto NDD, Basso RC, Meirelles AJA, Vladimir Oliveira J, Batista EAC, Meireles MAA (2012) Supercritical fluid extraction of grape seed: process scale-up, extract chemical composition and economic evaluation. J Food Eng 109:249-257

Rostagno MA, Manchon N, D'Arrigo M, Guillamon E, Villares A, Garcia-Lafuente A, Ramos A, Martinez JA (2011) Fast and simultaneous determination of phenolic compounds and caffeine in teas, mate, instant coffee, soft drink and energetic drink by high-performance liquid chromatography using a fused-core column. Anal Chim Acta 685:204-211

Santos DT, Veggi PC, Meireles MAA (2012) Optimization and economic evaluation of pressurized liquid extraction of phenolic compounds from jabuticaba skins. J Food Eng 108:444-452

Shi J, Yu J, Pohorly JE, Kakuda Y (2003) Polyphenolics in grape seeds-biochemistry and functionality. J Med Food 6:291-299

Silva LM (2003) Caracterização dos subprodutos da vinificação. Rev Millen 28:123-133

Takeuchi TM (2009) Supercritical extraction of macela, clove and vetiver: technological and economical aspects. Dissertation, University of Campinas, Brazil

Wagner H, Blad S (1996) Plant drug analysis: a thin layer chromatography atlas, 2nd edn. Springer, Munich

Xia EQ, Deng GF, Guo YJ, Li HB (2010) Biological activities of polyphenols from grapes. Int J Mol Sci 11:622-646

Yang T, Di W, Qing-An Z, Da-Wen S (2014) Ultrasound-assisted extraction of phenolics from wine lees: modeling, optimization and stability of extracts during storage. Ultrason Sonochem 21:706-715

Zamora-Ros R, Rabassa M, Llorach R, González CA, Andres-Lacueva C (2012) Application of dietary phenolic biomarkers in epidemiology: past, present, and future. J Agric Food Chem 60:6648-6657

\section{Submit your manuscript to a SpringerOpen ${ }^{\circ}$ journal and benefit from:}

- Convenient online submission

- Rigorous peer review

- Immediate publication on acceptance

- Open access: articles freely available online

- High visibility within the field

- Retaining the copyright to your article

Submit your next manuscript at $>$ springeropen.com 